Saudi Journal of Oral and Dental Research

Abbreviated Key Title: Saudi J Oral Dent Res

ISSN 2518-1300 (Print) |ISSN 2518-1297 (Online)

Scholars Middle East Publishers, Dubai, United Arab Emirates

Journal homepage: https://saudijournals.com/sjodr

\title{
Determination of Shear Bond Strength and Evaluation of Enamel Surface Changes Following Debonding of Different Ceramic Brackets: An-Vitro Study
} \author{
Varughese $^{6}$, Dr. Anjaly ${ }^{7}$ \\ ${ }^{1}$ Post graduate Malabar Dental College and Research Centre, Edappal, Malappuram, Kerala, India \\ ${ }^{2} \mathrm{Head}$ of the Department, Malabar Dental College and Research Centre, Edappal, Malappuram, Kerala, India \\ ${ }^{3,4}$ Reader, Malabar Dental College and Research Centre, Edappal, Malappuram, Kerala, India \\ ${ }^{5}$ Reader, Malabar Dental College and Research Centre, Edappal, Malappuram, Kerala, India \\ ${ }^{6,7}$ Senior Lecturer Malabar Dental College and Research Centre, Edappal, Malappuram, Kerala, India
}

Dr. Sajitha $\mathrm{R}^{1 *}$, Dr. Bejoy P Unni ${ }^{2}$, Dr. Lakshmi Lakshmanan ${ }^{3}$, Dr. Venith Jojee ${ }^{4}$, Dr. Parson Paul ${ }^{5}$, Dr. Sanju Thomas

DOI: $10.36348 /$ sjodr.2020.v05i02.002

| Received: 09.01.2020 | Accepted: 30.01.2020 | Published: 07.02.2020

*Corresponding author: Dr. Sajitha

\section{Abstract}

Introduction: Ceramic brackets exhibit generally high bond strength and enamel surface damage after debonding. Aim of the study: To evaluate and compare shear bond strength and enamel surface changes while de-bonding different ceramic bracket systems Materials and methods: Three types of ceramic brackets (polycrystalline Clarity; 3M Unitek, Monrovia, Calif; monocrystalline Inspire Ice; Ormco, Orange, Calif and Radiance; American orthodontics, USA) were bonded to extracted maxillary premolars, with Transbond XT light cure adhesive paste (3M Unitek). The sample consisted of 90 extracted maxillary premolar teeth. 15 bonded teeth of each type, were tested on UTM and 15 bonded teeth, were removed by pliers according to the manufacturers recommendations. After debonding with pliers ARI scores and SEM analysis of tooth surface and bracket base were evaluated under different magnifications (30X and 500X). Results: The mean SBS value of Inspire Ice, Radiance and clarity Advanced were 22.81 $\pm 2.02 \mathrm{MPa}, 17.93 \pm 1.63 \mathrm{MPa}$ and $17.28 \pm 1.45$ Mpa respectively. ARI score showed that most of the adhesive left on the tooth surface of monocrystalline brackets. SEM analysis showed that enamel surface changes in the form of open focal holes on tooth surface and globules were found on the corresponding bracket base. Conclusion: The highest SBS with minimum enamel surface damage observed on Inspire Ice.

Keywords: Ceramic bracket, Clarity, Inspire Ice, Radiance, SBS, SEM, ARI and enamel damage.

Copyright @ 2020: This is an open-access article distributed under the terms of the Creative Commons Attribution license which permits unrestricted use, distribution, and reproduction in any medium for non-commercial use (NonCommercial, or CC-BY-NC) provided the original author and source are credited.

\section{INTRODUCTION}

The In fixed orthodontics, earlier appliances were attached to the patients teeth by brackets and tubes with bands. After the introduction of etching technique by Michael $G$ Buonocore bonding of attachment to enamel was stared [1]. Newman introduced direct bonding technique as an alternative to banding in the field of Orthodontics [2]. In recent years adults are seeking esthetic orthodontic treatment. During early 1970's Plastic brackets were introduced in dentistry. These polycarbonate brackets had disadvantages of discoloration and slot distortion caused by water absorption [4, 17, 28].To compensate disadvantages of polycarbonate brackets, high grade medical polyurethane brackets and polycarbonate brackets reinforced with ceramic and ceramic brackets have been recently introduced [3]. Ceramic brackets were made of aluminium oxide and were available in Monocrystalline sapphire and polycrystalline ceramic brackets in orthodontics, since 1980's. This ceramic bracket has esthetically superior to plastic brackets. Ceramic brackets have certain advantages of color stability, high bond strength, and torque control than plastic brackets [6].

Monocrystalline brackets are more translucent than polycrystalline brackets [10]. Polycrystalline zirconia brackets $(\mathrm{ZrO})$ have greatest toughness and cheaper but opaque and less aesthetic than monocrystalline brackets [11]. High bond strength of ceramic brackets may causes problems of enamel surface fracture during debonding[7]. It is mainly due to bond failure occurs at the enamel adhesive interface .To overcome this limitation, a second generation brackets with mechanical base was introduced in 
1991(Transcend 2000, 3M Unitek, Monrovia, Calif). It has lower shear bond strength and causes less enamel surface fracture than the first generation, but It requires special debonding instruments [8]. In third generation (3M Unitek) collapsible bracket introduced in 1997 has a vertical slot, which help a consistent bracket failure mode during debonding, as in the same manner as metal brackets [9]. Bonding of ceramic brackets are done by three different methods consist of chemical, mechanical or combination of both. Mechanically retentive ceramic bracket are more desirable than chemically retentive brackets because second one shows higher bond strength. Higher bond strength causes more enamel surface damage after debonding [7]. So the manufacturers have continuously modified bracket base designs such as microcrystalline, mechanical ball, dove tail, dimpled, button etc and new debonding technique with different types of plier introduced in the market for their particular brand of brackets [22].

In this study consist of three ceramic brackets ; Clarity advanced poly crystalline ceramic brackets (3M Unitek, Monrovia, Calif) had microcrystalline mechanical base[13] and two monocrystalline ceramic brackets ; Inspire Ice (Ormco, Orange, Calif) and Radiance (American orthodontics, USA) are mechanically retained ceramic bracket with patented bead ball and patented quad matte respectively. Manual method of bonding of adhesive was done to the bracket base [14]. Enamel surface damage caused by debonding of ceramic brackets is more than that of metal brackets due to their higher bond strength [16]. The greater amount of enamel surface damage during debonding of ceramic bracket due to the presence of ceramic mesh, which has greater adhesion on enamel surface than other metal brackets [25].

Microscopic evaluation of tooth surfaces after debonding shows many scratches and rough surface. These surfaces provide potential site of plaque accumulation, stain and demineralization through microbial activity [24].

In recent years many types of ceramic bracket materials are available and it is necessary to determine the shear bond strength and intencity of enamel surface damage after debonding of various brackets.

This study was selected to determine the shear bond strength and intencity of surface damage when using these brackets in human teeth. For this study we used two monocrystalline bracket (Radiance and inspire Ice bracket) and one polycrystalline bracket (Clarity advanced) with mechanical base designs and to compare and measure the shear bond strength in universal testing machine and also determine enamel surface damage after debonding of these brackets with their corresponding pliers introduced by the manufacturer. Enamel surface and bracket base after debonding can be evaluated by SEM analysis. This study help to assess which ceramic bracket exhibits highest bond strength and causes minimal damage to enamel after debonding of these brackets clarity advanced, Inspire Ice and radiance.

\section{MATERIALS AND SUBJECTS}

Ninety extracted maxillary premolars were extracted for orthodontic purpose used as sample for this study and stored for seven days in $(0.1 \% \mathrm{wt} / \mathrm{vol})$ thymol-water solution at room temperature, for asepsis and dehydration prevention [22]. After this period, the remaining soft tissues, calculi and root-adhered bone fragments were removed. Teeth were stored in distilled water at $4^{0} \mathrm{C}$, which was replaced every seven days. All teeth had intact enamel surface with no caries and large restorations. Teeth selected were not pre-treated with chemical agents, such as hydrogen peroxide, formalin or fluoride. Prior to the start of the experiment, the teeth were rinsed and randomly assigned to three equal groups of 30 teeth in each group for three different bracket systems. A study by Hobson 2 et al. showed significant bond strength differences between upper and lower premolars. To obtain reliable results in enamel bond strength studies, the same tooth type from the maxillary or mandibular arch should be used and only maxillary premolars were included for this study.

Three types of Maxillary premolar ceramic brackets with 022" slot MBT series were selected : Clarity Advanced was manually pasted Poly crystalline $\mathrm{AlO}_{2}$ ceramic bracket (U45, 6400-611) with microcrystalline mechanical base design having base area of $11.69 \mathrm{~mm}^{2}$,Inspire Ice was clear monocrystalline $\mathrm{AlO}_{2}$ ceramic twin bracket having base area of $11.50 \mathrm{~mm}^{2}$ with patented bead ball bracket base[22] and Radiance was clear monocrystalline $\mathrm{AlO}_{2}$ ceramic twin bracket having base area of $15.1 \mathrm{~mm}^{2}$ with patented quad matte bracket base[31]. Identification of brackets is shown in (fig: $1 \mathrm{a}-\mathrm{c}$ ).

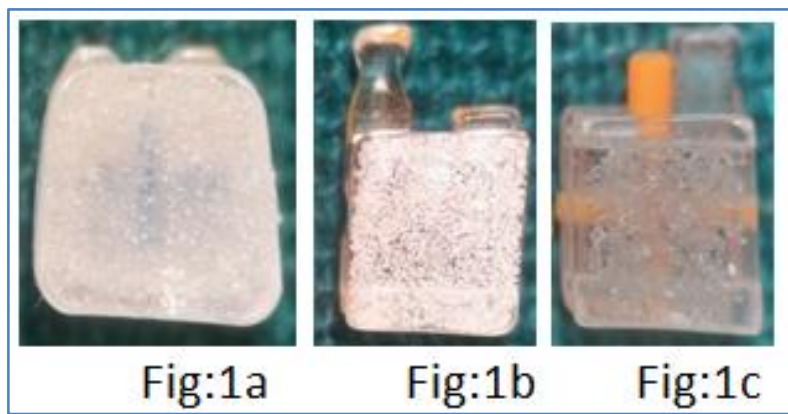

Fig-1: Clarity advanced, b- Inspire Ice and c-Radiance

All teeth were scaled and given a thorough prophylaxis was done by water and pumice without fluoride with a rubber cup for 5 seconds under slow speed. Each rubber cup was replaced after 5 prophylactic procedures [27]. All teeth were rinced and dried. Then bonding was done according to the manufacturer's instructions. The buccal enamel was 
etched for 30 seconds with a 37 per cent phosphoric acid gel (ORTHO-TECH), rinsed with water spray for 20 seconds and air-dried with oil-free compressed air. At this point, each tooth had a chalky- white appearance. The bonding Primer (Transbond XT; 3M Unitek, St Paul, Minn) was placed on the etched area. The teeth were then dried with air .The adhesive (Transbond XT; 3M Unitek, Calif) was applied to the bracket base. Then the bracket was fixed on to the tooth with a constant force at the ideal occluso-gingival and mesio-distal position [15]. Each tooth was light cured for 10 seconds using a halogen curing light. All bonded specimens were placed in distilled water for 12 hours at $37^{\circ} \mathrm{C}$ after bonding [22]. The shear bond strength of the samples was tested on a Universal Testing Machine (Tinius Olsen). Then debonding of all samples was done as stated by the manufacturer for determining ARI index of bracket base at 10x magnification of optical stereomicroscope and SEM analysis of enamel surface and bracket base for determining enamel surface changes after debonding of brackets by using their respective pliers.

The sample consisted of 90 extracted maxillary premolar teeth were randomly assigned to 3 groups. 30 bonded clarity advanced brackets, 30 bonded Inspire Ice brackets and 30 bonded Radiance brackets. 15 of each bracket types were tested on a universal testing machine to determine shear bond strength and 15 of each bracket type, were removed by pliers according to the manufacturers recommendations to compare the enamel surface changes with the help of SEM analysis.

\section{SHEAR TEST}

The shear bond strength of the samples was tested on a Universal Testing Machine. (Tinius Olsen). The force required to shear off the bracket was recorded in Newton at a crosshead speed of $1 \mathrm{~mm} /$ minute connected to a computer that recorded the results of each test. The specimen was held in lower jaw of the machine so that the bonded brackets base was parallel to the shear force direction. Force applying chisel was held in upper jaw and specimens was stressed in an occluso gingival direction at the bracket-tooth interface (fig-2). The force recorded in newton was converted in to Megapascals as a ratio of Newtons to surface area of brackets.

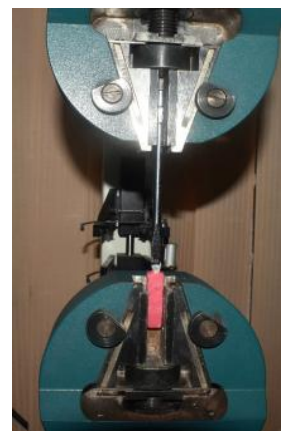

Fig-2: Sample mounted on UTM
Evaluation of adhesive remnent index on bracket base:

Clarity advanced brackets used in this study was debonded by conventional Weingart plier [22] (fig3a) (Skodi, Made in India) by placing the beaks of the plier mesio-distally and applying constant pressure (Fig: 3b)

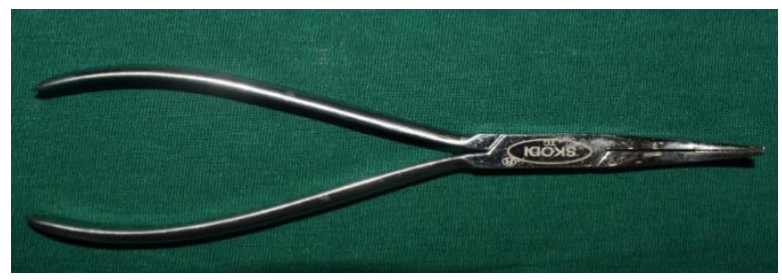

Fig-3a: Weingart plier for debonding clarity bracket

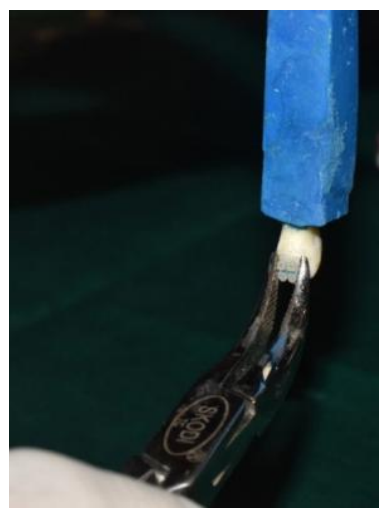

Fig-3b: Debonding clarity advanced bracket

Inspire Ice monocrystalline brackets used in this study were debonded by using ormco \# 866-4020 debonding plier (fig-4b) by position the jaws of the instrument behind the gingival and occlusal tie-wings of the bracket. Squeeze the instrument handle to close the jaws around the bracket body. Continue squeezing the instrument handle to engage the wedge and advance it toward the bracket pad. As the wedge comes into contact with the tooth, it will peel the bracket from the tooth (fig: 4a).



Fig- 4a: Debonding of inspire ice bracket

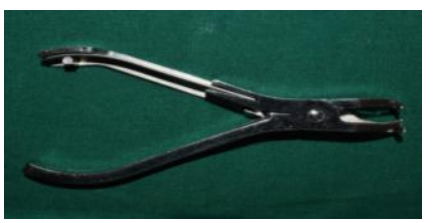

Fig- 4b: ormco \# 866-4020 debonding plier 
Radiance brackets used in this study were debonded by using the recommended \#001-017405, Radiance plus pliers (Fig-5b) by placing the opposing tips of the pliers occlusal and gingival under the tie wings of the bracket, while applying constant pressure to the handles (fig:5a).

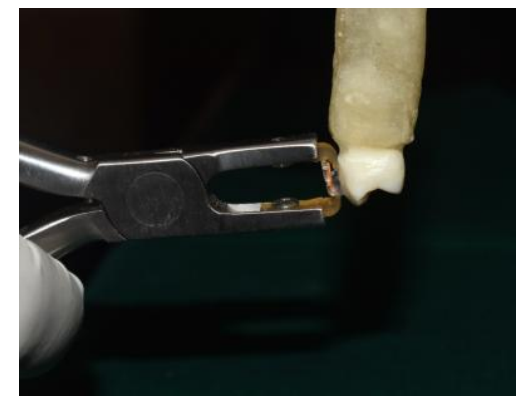

Fig-5a: Debonding of radiance bracket

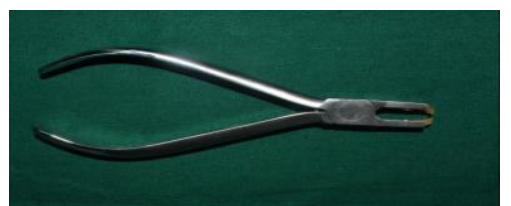

Fig-5b: \#001-017405, Radiance plus pliers

After debonding all bracket base were examined by optical stereomicroscope of 10 times magnification, with the following classifications consist of 4-point scale from 0 to 3 :

SCORE: 0 - No adhesive left on the bracket base;

SCORE: 1- Less than half of the adhesive left on the bracket base

SCORE: 2-More than half of the adhesive remained on the bracket base

SCORE: 3 - All adhesive was remained on the bracket base [23].

Scores were given by repeated checking of bracket base independently by 3 observers in oral pathology department and rechecked this score after 3 days by the same examiner. From this rechecked data more accurate and similar value were taken as score of each bracket base.

\section{Sem analysis}

Tooth surfaces and bracket base were examined by used to determine the site of the enamel surface and bracket base after debonding of bracket by the use of each group of brackets were debonded with their corresponding pliers recommended by their manufacturers such as \#001-017405 debonding pliers designed by American orthodontics for Radiance, \#8664020 debonding plier designed by Ormco for inspire ice and Weingart plier designed by SKODI, in India for clarity advanced bracket.

After ARI score evaluation, enamel surface damage was evaluated with the help of Scanning Electron Microscope (JEOL; MODEL-JSM6390) at increasing magnifications (30 and $500 \mathrm{x}$ ). The $30 \mathrm{x}$ magnification provide whole bracket base and tooth surface area [25]. SEM analysis provided only qualitative evaluation. In SEM analysis, initially the brackets were debonded, then the tooth surface and bracket base were mounted on aluminium stubs with their bases facing up, sputter coated with a $100 \mathrm{~A}^{0}$ layer of gold (Autofine coater JFC 1600, JEOL, Japan) and analysed using a high vaccum SEM (JSM 6390 LA, JEOL, Japan) that captured secondary electron images at $15 \mathrm{kV}$ using $12 \mathrm{~mm}$ working distance. SEM of tooth surface image was a mirror image of SEM of bracket base image of same sample

\section{STATISTICAL ANALYSIS}

Data was analyzed using the statistical package SPSS 22.0 (SPSS Inc., Chicago, IL) and level of significance was set at $\mathrm{p}<0.05$.Descriptive statistics was performed to assess the mean and standard deviation of the respective groups. Normality of the data was assessed using Shapiro Wilkinson test. Inferential statistics to find out the difference between the groups was done by one way ANOVA and Tukey's HSD posthoc test. ARI score comparison of proportion done using Chi square statistics.

\section{RESULTS}

Inspire Ice and Radiance bracket were used as experimental group and Clarity Advanced was used as control group. Shear bond strengths and debonding forces of these three ceramic brackets were evaluated by universal testing machine (Tinius Olsen) [22].The SBS (MPa) value for all 15 samples in each of the three groups are displayed in (Table 1). The mean SBS for the Clarity advanced; Inspire ice and Radiance were 17.28, 22.81, and $17.93 \mathrm{MPa}$, respectively. The repeated-measures ANOVA found a significant difference between the groups and a $\mathrm{P}$ value $<0.05$. Result showed that (Table-2) there was statisticaly significant and higher SBS of Inspire Ice than Clarity advanced and Radiance ceramic brackets and also showed the clarity advanced and radiance had almost similar value, but slightly higher in Radiance bracket. 
Table-1: Shear bond strength value

\begin{tabular}{|c|r|r|r|}
\hline & \multicolumn{1}{|c|}{ Group A } & \multicolumn{1}{c|}{ Group B } & Group C \\
\hline & Clarity & Inspire Ice & Radiance \\
\hline sample 1 & 14.81 & 22.64 & 19.11 \\
\hline sample 2 & 17.53 & 18.26 & 19.67 \\
\hline sample 3 & 17.95 & 23.61 & 15.27 \\
\hline sample 4 & 18.37 & 23.26 & 15.47 \\
\hline sample 5 & 19.51 & 20.17 & 16.44 \\
\hline sample 6 & 16.25 & 22.56 & 19.14 \\
\hline sample 7 & 16.39 & 24.86 & 19.81 \\
\hline sample 8 & 17.91 & 25.43 & 17.68 \\
\hline sample 9 & 18.79 & 22.35 & 16.58 \\
\hline sample 10 & 18.66 & 21.78 & 19.11 \\
\hline sample 11 & 16.22 & 22.86 & 19.29 \\
\hline sample 12 & 18.36 & 24.41 & 18.39 \\
\hline sample 13 & 17.54 & 20.62 & 16.68 \\
\hline sample 14 & 14.66 & 25.61 & 16.44 \\
\hline sample 15 & 16.25 & 23.82 & 19.87 \\
\hline MEAN & 17.28 & 22.816 & 17.93 \\
\hline SD & 1.451369 & 2.020671 & 1.639917 \\
\hline $1^{\text {st }}$ quartile & 16.25 & 22.065 & 16.51 \\
\hline $3^{\text {rd }}$ quartile & 18.365 & 24.115 & 19.215 \\
\hline IQR & 2.115 & 2.05 & 2.705 \\
\hline
\end{tabular}

Table-2: Oneway anova summary statistics

\begin{tabular}{|l|l|l|l|l|l|}
\hline $\begin{array}{l}\text { Source of } \\
\text { variation }\end{array}$ & $\begin{array}{l}\text { Sum of } \\
\text { squares }\end{array}$ & df & Variance & F & P \\
\cline { 1 - 5 } $\begin{array}{l}\text { Between } \\
\text { Groups }\end{array}$ & 274.0890 & 2 & 137.0445 & \multirow{2}{*}{46.5094} & $0.001^{*}$ \\
\cline { 1 - 1 } $\begin{array}{l}\text { Within } \\
\text { Groups }\end{array}$ & 123.7572 & 42 & 2.9466 & & \\
\cline { 1 - 4 } Total & 397.8462 & 44 & & & \\
\hline
\end{tabular}

One way Anova shows significant difference exist between the groups regarding shear bond strength $(p<0.05)$

Table-3: Tukey's hsd poc hoc analysis

\begin{tabular}{|l|l|l|l|}
\hline Group comparison & DIFFERENCE & 95\% CONFIDENCE INTERVAL & P VALUE \\
\hline GROUP 1 vs GROUP 2 & 5.5300 & 4.0072 to 7.0528 & $\mathbf{0 . 0 0 0 0} *$ \\
\hline GROUP 1 vs GROUP 3 & 0.6500 & -0.8728 to 2.1728 & $\mathbf{0 . 5 5 8}$ \\
\hline GROUP 2 vs GROUP 3 & -4.8800 & -6.4028 to -3.3572 & $\mathbf{0 . 0 0 0 0} *$ \\
\hline
\end{tabular}

$* \mathrm{P}<0.05$ is statistically significant

Post hoc analysis using Tukey's HSD test shows the significant difference between Group 1vs 2 AND Group 2 vs 3

\section{INTERPRETATION}

The One way ANOVA followed by post hoc analysis test was used to find out the statistical significance between the groups. It is found out that there is a significant difference exist between the groups $(\mathrm{p}<0.05)$. Post hoc analysis of the pair wise groups also showed statistical significance $\mathrm{p}<0.05$ ) (Group A vs B, Group A vs C and Group B vs C). Highest and lowest bond strength observed in Group B and Group A respectively as shown in the table. The amount of adhesive remaining on the bracket base was evaluated using 4-point ARI score showed in table-4. 


\begin{tabular}{|c|c|c|c|c|}
\multicolumn{5}{|c|}{ Table-4: Ari score of bracket base } \\
\hline Sample Number & Radiance & Inspire Ice & Clarity Advanced & Chi Square Value \\
\hline 0 & $4(26.6 \%)$ & $7(46.6 \%)$ & $2(13.3 \%)$ & \multirow{2}{*}{$0.04 *\left(\mathrm{X}^{2}=12.5\right)$} \\
\hline 1 & $7(46.6 \%)$ & $5(33.3 \%)$ & $5(33.3 \%)$ & \\
\hline 2 & $3(20 \%)$ & $2(13.3 \%)$ & $6(40 \%)$ & \\
\hline Total & $1(6.8 \%)$ & $1(6.8 \%)$ & $2(13.3 \%)$ & \\
\hline \multicolumn{7}{|c|}{ SCORE: 0 - No adhesive remaining on the bracket base; }
\end{tabular}
SCORE: 1- Less than half of the adhesive on the bracket base SCORE: 2-More than half of the adhesive on the bracket base SCORE: 3 - All adhesive remaining on the bracket base [23]

ARI scores 0 showed that no adhesive remaining on the bracket base 4 Radiance, 7 Inspire Ice and 2 Clarity advanced brackets sample and Score 1 showed that less than half of composite only on bracket base of 7Radiance, 5 Inspire Ice and 5 Clarity advanced brackets sample. Only 1 specimen of each of the Radiance and Inspire Ice have all the residual adhesive remaining on their bracket base score 3 . ARI score 2 showed that more than half of composite on bracket base of 3 Radiance, 2 Inspire Ice and 6 Clarity advanced brackets sample.

Tooth surface examination: There was no macroscopic evidence of enamel surface damage seen after debonding of brackets. When the tooth surfaces and bracket base undergo SEM analysis, there were small holes on the tooth surface adhesive remnants and small globules of enamel particle present on bracket base of the same sample. The open holes were large on clarity advanced tooth surface (fig:6a and 6c) and large globules on respective bracket surface (fig: $6 \mathrm{~b}$ and $6 \mathrm{~d}$ ), Medium sized holes on radiance tooth surface (fig: $7 \mathrm{a}$ and $7 \mathrm{~b}$ ) and medium sized globules on bracket base (fig: 7c and 7d) and very small holes on inspire Ice tooth surfaces (fig: $8 \mathrm{a}$ and $8 \mathrm{~b}$ ) and small globules on bracket base (fig: $8 \mathrm{c}$ and $8 \mathrm{~d}$ ) at $30 \mathrm{x}$ and $500 \mathrm{x}$ magnification respectively.

Sem images at 30x and 500x magnifications

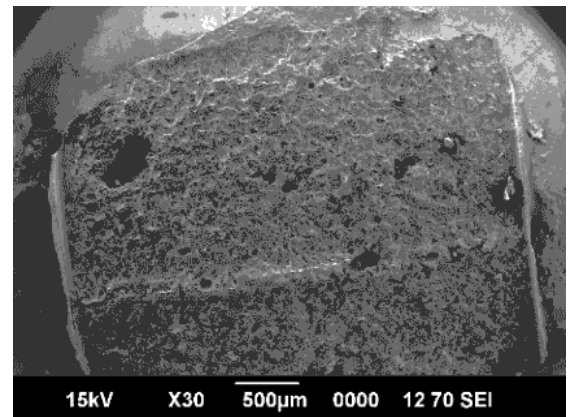

Fig-6a: Clarity tooth surface at 30x magnification shows holes

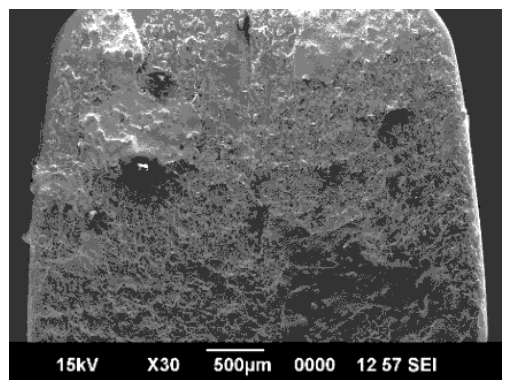

Fig-6b: Clarity bracket base at 30x magnification shows globules

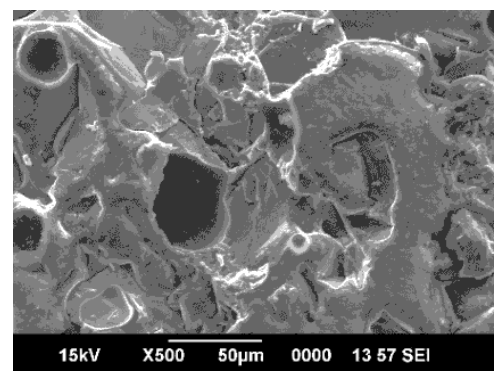

Fig-6c: Clarity tooth surface at 500x magnification shows holes

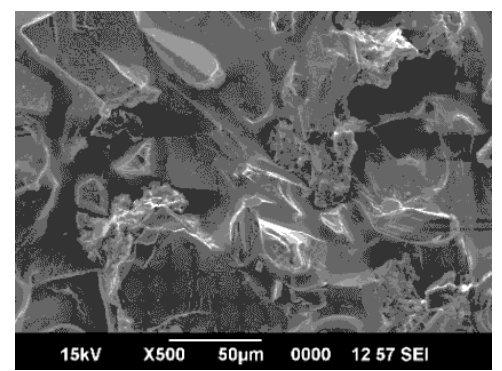

Fig-6d: Clarity bracket base at 500x magnification shows globules

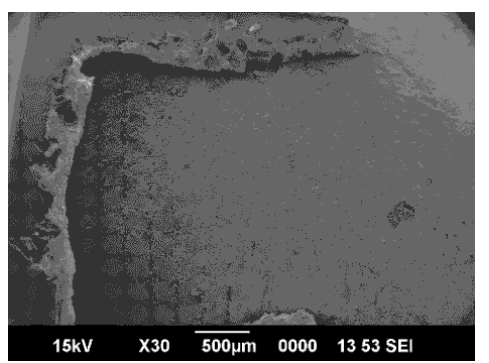

Fig- 7a: Radiance tooth surface at 30x magnification shows holes 


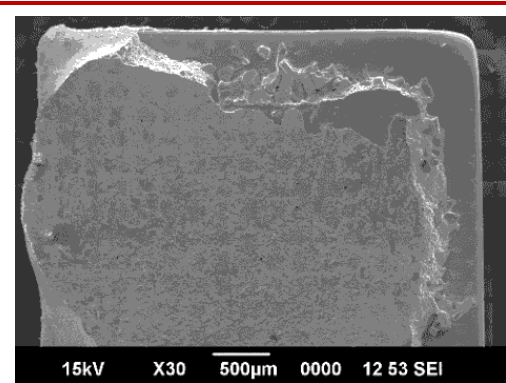

Fig-7b: Radiance bracket base at 30x magnification shows globules

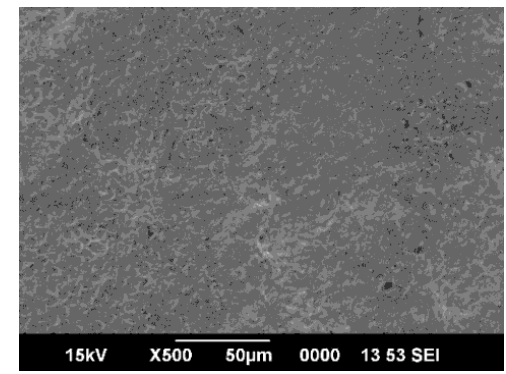

Fig- 7c: Radiance tooth surface at 500x magnification shows holes

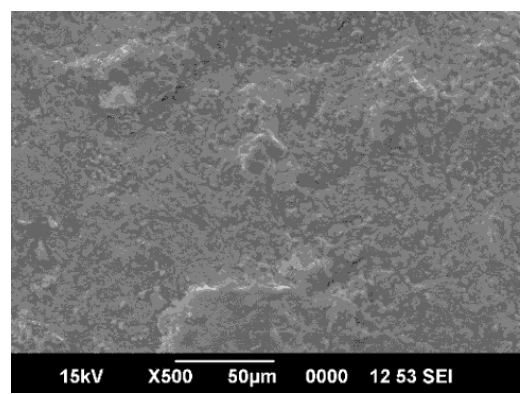

Fig-7d: Radiance bracket base at 500x magnification shows globules

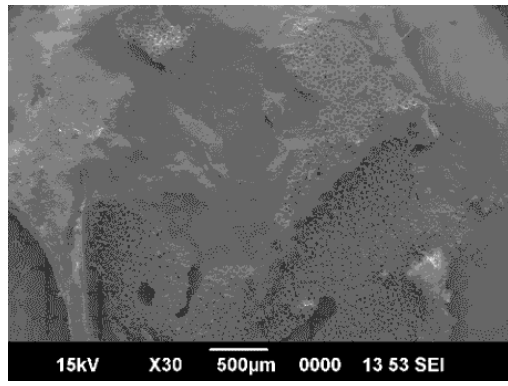

Fig- 8a: Inspire Ice tooth surface at 30x magnification shows holes



Fig-8b: Inspire Ice bracket base at 30x magnification shows globules

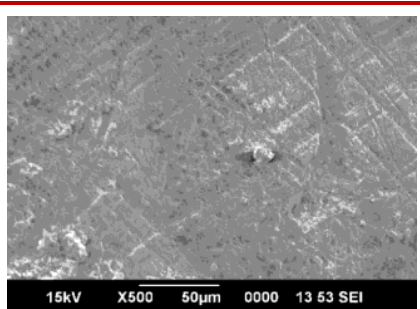

Fig-8c: Inspire Ice tooth surface at 500x magnification shows holes

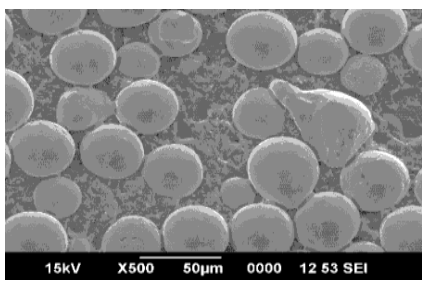

Fig-8d: Inspire Ice bracket base at 500x magnification shows globules

\section{DISCUSSION}

Different types of ceramic brackets are available in recent days. In general, ceramic brackets are composed of aluminium oxide, which may be single crystal (monocrystalline) or polycrystalline. Among these monocrystalline brackets are more expensive and have more esthetics than polycrystalline brackets. Clarity is a collapsible polycrystalline bracket. Inspire Ice and Radiance is collapsible monocrystalline bracket, which has greater optical clarity. Ceramic bracket debonding causes considerable amount of enamel loss due to its high shear bond strength [16]. Several authors tried to reduce bond strengths by changing the adhesive paste, etchants, or the etching times and some manufacturer recommends different types of debonding plier. But no consistent method should not found to reduce the enamel fracture after debonding the brackets. The lack of ductility of ceramic brackets may generate stress in the adhesive-enamel interface that may produce enamel cracks after debonding. Ceramic brackets using chemical retention cause enamel damage more often than those using mechanical retention [17, 19, 20]. This damage occurs probably because the location of the bond breakage is at the enamel-adhesive interface rather than at the adhesive-bracket interface [17-20]. Microscopic evaluation of tooth surfaces shows many scratches and rough surface after debonding. These surfaces could potential site of plaque accumulation, stain and demineralization through microbial activity. Calcium loss from the enamel surface particularly can result in dental erosion [24]. All type of ceramic brackets have problems during debonding, mechanically retained brackets have adequate bond strength and cause minimal enamel damage $[16,30]$.

The purpose of this in vitro study was to compare the shear bond strength, Adhesive remnants index on bracket base and enamel surface damage after debonding of three ceramic brackets (Clarity advanced, Inspire Ice and Radiance). All these brackets selected for this study have mechanically retained base designs. 
In present study, result showed that there was statisticaly significant and higher SBS of Inspire Ice than Clarity advanced and Radiance ceramic brackets. Park MG repoted in their study that the bead base surface of Inspire Ice has many round monocrystalline beads, which is compleately distributed over the base, there was small undercuts in between the beeds, which helps in mechanical interlocking of the adhesive resin resulting in higher SBS than that of other brackets[33]. Result (table 1) showed that shear bond strength of clarity advanced and radiance had almost similar value, but slightly higher in Radiance bracket. Shear bond strength of monocrystalline brackets greater than that of polycrystalline brackets [32, 33]. Result showed that SBS of Inspire Ice was greater than that of Radiance. Lopez JL reported in his study that bond strength inversally proportional to the bonding area of bracket [34]. The average bracket-base areas of Radiance and Inspire Ice brackets were 15.1 and $11.50 \mathrm{~mm}^{2}$ respectively [13, 22, 31].

In recent times to maintain the enamel structure in its pretreatment state and to reduce the iatrogenic damage, correct bonding and debracketing techniques with their respective pliers introduced by their manufacturers. The present study compared the debonding characteristics of a recently introduced debonding instrument designed to debond Inspire Ice and Radiance with clarity advanced bracket debonded using weingart pliers.

ARI scores represent the site of bond failure after debonding at the bracket adhesive interface or at the enamel adhesive interface. Macroscopic evaluation showed that cohesive failure occurs in the adhesive system. In the present study ARI score 0 indicating the adhesive failure at bracket-adhesive interface with distinct impression of the bracket mesh on enamel surface. ARI score 3 indicating the adhesive failure at enamel-adhesive interface. ARI score 1 and 2 indicating all the three types of bond failure. The cohesive adhesive failure occurs in 2 Radiance, 2 Inspire Ice and 4 Clarity advanced sample.

ARI scores (table 4) indicated and supported to the study of Liu $\mathrm{J} \mathrm{K}$ et al that the two debonding pliers to leave most of the adhesive remaining on the enamel surface and small amount of composite only on bracket base[26]. ARI score 0 and 1 indicated to leave significant amount of the adhesive remaining on the tooth surface and fewer amounts on bracket base [26]. This result showed that with the new debonding instrument, left more residual adhesive on the enamel surface than the use of weingart pliers. Only 1 specimen of each of the Radiance and Inspire Ice have all the residual adhesive remaining on their bracket base.This result supported to the study of Suliman et al. and contradict ory to the study of Ostby et al. showed that the monocrystalline ceramic brackets had most of the adhesive remaining on the tooth surface with well- defined outline but in case of polycrystalline ceramic bracket, less than $47 \%$ of sample showed most of the adhesive left on the tooth surface and in other half less than half of the adhesive left on the tooth surface[5].

On SEM analysis, in this study showed that ceramic brackets with low bond strength having clarity advanced brackets shows more enamel fracture than the other two brackets. These results supported to the study of Liu et al. and Chen et al. reported that debonding collapsible ceramic brackets with the pliers recommended by the manufacturers are safer[22,26]. Only 2 enamel fractures were noted when debonding the Inspire Ice brackets, 3 for Radiance and 6 for Clarity advanced brackets. The bond failure at the bracket-adhesive interface reduces the risk of enamel fracture. This result indicated that it is safe to debond the ceramic bracket with the pliers recommended by the manufacturers.

\section{ACKNOWLEDGEMENT KUHS UNIVERCITY}

\section{CONCLUSION}

The present study was done to evaluate and compare the shear bond strength and enamel surface damage after debonding of different ceramic brackets such as Clarity advanced, Radiance and Inspire Ice. The study led to the following conclusions:

1) The shear bond strength of Clarity advanced, Radiance and Inspire Ice was 17.28MPa, 17.93MPa and $22.816 \mathrm{MPa}$ respectively. The repeatedmeasures ANOVA found a significant difference between the groups and a P value 0.001. A Tukey's post hoc test found that there was no significant difference between the clarity advanced group and the Radiance.

2) The amount of adhesive remaining on the bracket base was evaluated using 4-point ARI score showed that more than $75 \%$ of Radiance and Inspire Ice brackets have ARI scores of 0 and 1, but Clarity advanced only below $50 \%$ of these scores. That means most of the adhesive left on the tooth surface indicated that the bond failure occurs at the bracket-adhesive interface reduces the risk of enamel fracture with the help of pliers recommended by the manufacturers.

3) In this study SEM analysis showed that Only 2 enamel fracture were noted when debonding the Inspire Ice brackets, 3 for Radiance and 6 for Clarity advanced brackets. This result indicated that it is safe to debond the ceramic bracket with the help of pliers recommended by the manufacturers.

\section{REFERENCE}

1. Buonocore, M.G. (1955). A simple method of inceasing the adhesion of acrylic filling materials to enamel surfaces. J Dent Res, 849-853. 
Sajitha R et al; Saudi J Oral Dent Res, Feb 2020; 5(2): 90-98

2. Newman, G.V. (1965). Epoxy adhesives for orthodontic attachments: progress reports. American Journal of Orthodontics, 51, 901-912.

3. Russell, J.S. (2005). Aesthetic orthodontic brackets. J Orthod. 32, 146-163.

4. Newman, G. (1969). Adhesion and orthodontic plastic attachments. Am J Orthod, 56, 573-588.

5. Suliman, S.N., Trogen, T.M., Tantbirojn, D., Versluis, A. (2015). Enamel loss following ceramic bracket debonding: a quantitative analysis in-vitro. Angle orthodontist, 85(4), 651-656.

6. Sinha, P.K., Nanda, R.S. (1997). Esthetic orthodontic appliances and bonding concerns for adults. Dent Clin North Am, 41, 89-109

7. Viazis, A.D., Cavanaugh, G., Bevis, R.R. (1990). Bond strength of ceramic brackets under shear stress: An in vitro report. Am J Orthod Dentofac Orthop, 98(3), 214-221.

8. Redd, T.B., Shivapuja, P.K. (1991). Debonding ceramic brackets-Effects on enamel surface. $J$ ClinOrthod, 25, 475-481.

9. Bishara, S.E., Olsen, M.E., Wald, L.V.(1997). Evaluation of debonding characteristics of a new collapsible ceramic bracket. AJO, 112, 552-559.

10. Ashish, K., Ragni, T., Aftab, A. (2017).Recent advancements in orthodontic brackets-A Review. Indian journal of orthodontics and Dentofacial research, 3(3), 129-135.

11. Azzeh, E., Feldon, P.J. (2003). Laser debonding of ceramic brackets: a comprehensive review. Am J orthod Dentofac Orthop, 123, 79-83.

12. Kusy, R.P. (2002). Orthodontic Biomaterials: From the past to the present. Angle Orthod, 72, 501-512.

13. Ansari, M.Y., Agarwall, D. K., Guptha, A., Bhattacharya, P., Ansar, J., Bhandari, R. (2016). Shear bond strength of ceramic brackets with different base designs: comparative in -vitro study. JCDR, 10(11), ZC64-68.

14. Amstrong, D., Shen, G. (2007). Excess adhesive flash upon bracket placement. Angle Orthod, 77, 1101-1108.

15. Lee, M., Kanavaks, G. (2016). Comparison of shear bond strength and bonding time of novel flash-free bonding system. Angle Orthod, 86(2), 265-270.

16. Guess M.B., Watanabe, L.G., Beck, F.M., Gnall, M.G. (1988). The effect of silane coupling agents on the bond strength of polycrystalline ceramic brackets. J Clin Orthod, 22:788-792.

17. Bishara, S.E., Trulove, T.S. (1990). Comparisons of different debonding techniques for ceramic brackets: an in vitro study, Part I. AJO, 98, 145153.

18. Bishara, S.E., Trulove, T. (1990). Comparisons of different debonding techniques for ceramic brackets: an in vitro study. Part II. Findings and clinical implications. AJO, 98, 263-273.

19. Bishara, S.E., Fehr, D.E. (1993). Comparisons of the effectiveness of pliers with narrow and wide blades in debonding ceramic brackets. AJO, 103, 253-257.

20. Bishara, S.E., Fehr, D.E. (1997). Ceramic brackets: something old, something new, a review. Seminars in Orthodontics, 3,178-188.

21. Bishara, S.E., Fehr, D., Jacobsen. J. A. (1993). Comparative study of the debonding strengths of different ceramic brackets, enamel conditioners, and adhesives. AJO, 104, 170-179.

22. Hsing-Yu, C., Ming-Zen, S.U., Hsin-Fu Frank, C. (2007). Effects of different debonding techniques on the debonding forces and failure modes of ceramic brackets in simulated clinical set-ups .AJO, 132, 680-686.

23. Bishara, S.E., Olsen. M.E., VonWald, L., Jakobsen, J.R. (1999). Comparison of the debonding characteristics of two innovative ceramic bracket designs. AJO, 116, 86-92.

24. Ten Cate, J.M., Imfeld, T. (1996). Dental erosion, summary. Eur J Oral Sci, 104, 241-244.

25. Huib Berghauser Pont., Mutlu Ozcan., Bora bagis. (2010). Loss of surface enamel after bracket debonding: An in-vivo and ex-vivo evaluation. AJO, 138, 387.e1-387.e9

26. Liu, J.K., Chung, C.H. (2005). Bond strength and debonding characteristics of a new ceramic bracket. AJO, 128, 761-765.

27. Flavia Mitiko Fernandez., Kitahara-Ceia., Jose Nelson Mucha., Marques dos Santos. P. (2008). Assessment of enamel damage after removal of ceramic brackets. Am J Orthod Dentofacial Orthop, 134, 548-555.

28. Harzer, W., Bourauel, C., Gmyrek, H. (2004). Torque capacity of metal and polycarbonate brackets with and without a metal slot. Eur $J$ Orthod, 26, 435-441.

29. Sadat khonsari, R., Moshtaghy, A., Bauss, O. (2004). Torque deformation characteristics of plastic brackets: a comparative study. J Orofac Orthop, 65, 26-33.

30. Swartz, M.L. (1988).Ceramic brackets. J Clin Orthod, 22, 82-88.

31. Javaid C., Yasamin, F.J. (2016). Comparison of bond strength of metal and ceramic brackets bonded with conventional and high -power LED light curing units.www.jdt.tums.ac.ir, 13(6),423430.

32. Maryam, H., Tahereh, H.N. (2007). Comparison of debonding characteristics of metal and ceramic orthodontic brackets to enamel: An in-vitro study. AJO,132,675-679

33. Park, M.G. (2013).Effect of a DPSS laser on the shear bond strength of ceramic brackets with different base designs. Lasers Med sci. 28,14611466

34. Lopez. J.L. (1980). Retentive shear strengths of various bonding attachments bases. AJO, 77,669678. 